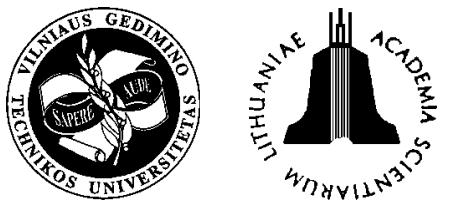

ISSN 1648-4142 TRANSPORT

http:/www.vtu.lt/english/editions

\title{
THE MODELLING OF THE LOGISTICAL NETWORK OF ON-LINE GROUPED GOODS
}

\author{
Andrius Jaržemskis \\ Dept of Transport Management, Vilnius Gediminas Technical University, Plytinès g. 27, LT-10105 Vilnius-16, \\ Lithuania.Tel.:370 5 2699714. E-mail: andrius.j@omni.lt
}

Received 2003-09-02; accepted 2004-02-17

\begin{abstract}
The article investigates functional interrelations between the carriage of on-line grouped goods and the structure of the logistical network. In order to forecast the flows of on-line grouped goods the indirect model has been chosen which enables us to evaluate two important aspects: the first one is the evaluation of the structure of the goods origins in terms of trading regions as well as the other factors determining the formation of flows of goods. The second one is concerned with the structure of the transport network. A technological tool which helps to optimize the carriage of grouped goods is the process of planning on-line grouped goods carriage routing in accordance with the indirect forecast of demand and supply of goods market.
\end{abstract}

Keywords: grouped goods, flow of goods, trading regions.

\section{Introduction}

The purpose of this article is to device a model which is necessary to foresee the flows for the transportation of on-line grouped goods.

With reference to the publications of the authors as well as having evaluated the way the indirect forecasting is applied in passenger's transportations when analyzing the need and origin of communication [1-3], the forecasting algorithm will be presented as well as the formulation of the task of forecast need for goods carriage.

\section{The formulation of the condition for the carriage of on-line grouped goods}

In the last years the size of consignments is falling gradually. When attempting to maintain a high coefficient of loading of transport means, greater attention should be paid to grouped goods [4].

Let us formulate the task of the need for the carriage of goods in the transport network. Fig demonstrates our given network fragment $G$, consisting of links $N$ and nodes $M$. Terminals as the nodes of the transport network are marked $k_{i}$. In this case link $\left(k_{6}, k_{9}\right)$ is a railway, other links are roads. The nodes $k_{1}, k_{2}, k_{3}, k_{4}, k_{5}, k_{7}, k_{8}, k_{10}, k_{11}$ are terminals of road transport which can belong either to transport or logistical companies, or to consignors/consignees of goods, i.e. manufacturing or trading companies. The nodes $k_{6}, k_{9}$ are multimodal terminals where goods can be reloaded: a) from rail into road transport means; b) from road into rail transport means; c) from one road transport means into another one; d) railway carriages can be reattached from one train to another one (in case of sorting out).

Let us now analyze the possibility of goods group-

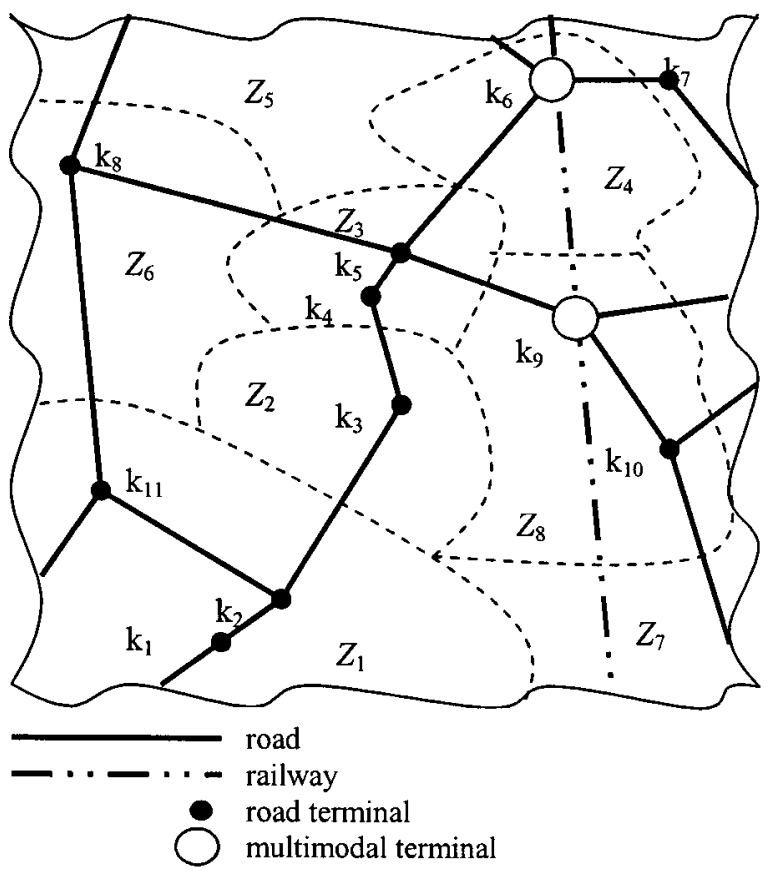

A fragment of the transport network 
ing given in Fig fragment of the transport network.

Transport companies tend to have loyal clients and a flow of goods more stable because as the volume of goods fluctuates a lot, it becomes more difficult to organize the carriage and forecast the need for the transport means, their characteristics. As the size of consignments is diminishing, there appears a possibility of minimizing of volume fluctuations, i.e. grouping goods in accordance with the direction of the destination point. Thus, peculiar chains for grouped goods are formed. For example, a transport company carrying goods from $k_{1}$ to $k_{6}$ knows about the need to transport goods from $k_{2}$ to $k_{5}$ and from $k_{4}$ to $k_{6}$. Let us mark single carriages of the goods $\Omega_{j}\left(k_{1}, k_{6}\right)$, $\Omega_{j}\left(k_{2}, k_{5}\right)$ and $\Omega_{j}\left(k_{4}, k_{6}\right)$, where $\Omega$ reflects the amount of the goods $j$ - carriage. On-line grouping of goods should meet four requirements:

a) Adequacy of route:

$$
\begin{aligned}
& \left(k_{2}, k_{5}\right) \in\left(k_{1}, k_{6}\right) ; \\
& \left(k_{4}, k_{6}\right) \in\left(k_{1}, k_{6}\right) .
\end{aligned}
$$

b) Adequacy of time $\Theta\left(\Omega_{j}\right)$ of $j$-carrying of goods:

$$
\Theta\left(\Omega_{j}\left(k_{1}, k_{6}\right)\right) \cong \Theta\left(\Omega_{j}\left(k_{2}, k_{5}\right)\right) \cong \Theta\left(\Omega_{j}\left(k_{4}, k_{6}\right)\right) .
$$

A possible time inadequacy error can be different in each separate case and it has to meet the needs of goods consignors and consignees.

c) Volume adequacy condition:

$$
\Omega_{j}\left(k_{1}, k_{6}\right)+\Omega_{j}\left(k_{2}, k_{5}\right)+\Omega_{j}\left(k_{4}, k_{6}\right) \leq \Omega_{\mathrm{a} / \mathrm{m}},
$$
riage.

$\Omega_{\mathrm{a} / \mathrm{m}}$ - the capacity of a transport means for car-

d) The condition ensuring the adequacy of legal means.

Having met the above mentioned condition, goods can be grouped by routes. In the long run, having the routes settled, we can also form a fixed route for carrying on-line grouped goods. For the sake of simplicity in our further modelling we will sign the logistical functions between adjacent terminals $\left(k_{i}, k_{i+x}\right)$ as $l_{j}$.

\section{The task of forming a network for carrying on-line grouped goods}

On-line grouped goods could be carried by different modes of transport. Let us assume that we have a fragment of the transport network $G[K ; L]$. We are going to evaluate a possibility of building a logistical chain $\left(k_{8}\right.$, $\left.k_{5}, k_{9}, k_{10}\right)$, for carrying on-line grouped goods. Its building will crate a possibility of on-line grouping of goods at terminal $k_{5}$ (by combining directories north-south and east-west) as well as a possibility of delivering smaller goods by grouping them into consignments at terminal $k_{9}$, where goods further are carried by rail.

When forecasting the carriage of goods, it is expedient to identify the peculiarities of the territory being planned and investigated. The territory is being planned in the way which can provide us with possibilities of appearing of potential consignors and consignees. The territory under investigation is subdivided into trading regions. Fig illustrates the fragment of the transport network $G[N ; M]$ with marked territories, i.e. trading regions $Z_{j}$. The size of a region is a very important criterion for establishing the interaction between the region trading subject located in this particular region and forecasting its future development possibilities.

A region can be described as a complete full set $\mathrm{X} \times \mathrm{Y}$. A complete set of regions $P=\left\{Z_{1}, \ldots, Z_{\text {p.max }}\right\}$ is called a territory under development, when the following requirement is met:

$$
\forall_{1 \leq i, j \leq p \cdot \max , i \neq j} Z_{i} \cap Z_{j}=\varnothing .
$$

A complete set of trading regions $T=\left\{Z_{1}, \ldots, Z_{\text {t.max }}\right\}$ is called a territory under investigation, when the following requirement is met:

$$
\forall_{1 \leq i, j \leq t . \max , i \neq j} Z_{i} \cap Z_{j}=\varnothing .
$$

The structure and peculiarities of a territory are the main data to form the need for carrying grouped goods. It can be argued that statistical data provide us with the peculiarities of the territory being investigated which in its turn encompasses the territory being planned.

The structure of a territory $S=(P, T, X, E, W)$ is composed of the following elements: a) the territory being planned $P$; b) the territory under investigation $T$, where $P \subseteq T$; c) $X: T \rightarrow N$, i.e. a name granted to each trading region of the territory being researched; d) $E: P \rightarrow N$, the number of enterprises attributed to each trading region of the territory being planned; e) $W: P \rightarrow N$, The turnover of on enterprises dispatched and accepted goods of each trading region located in the territory is being planned. Here:

$$
\begin{aligned}
& P=\left(Z_{6}, Z_{3}, Z_{8}\right), \\
& T=P \cup\left(Z_{1}, Z_{2}, Z_{4}, Z_{5}, Z_{7}\right) .
\end{aligned}
$$

The network of chains carrying goods in the fragment $G[K ; L]$ of the transport network located across the territory being researched $T$ can be described as follows: $G_{R}=\left(K, L, L_{R}, I, X Y, Q, B\right)$. This fragment consists of:

a) $K$ - a complete set of transport terminals belonging to the chains along which grouped goods flow.

b) $L$ - a complete set of links defined as $l \in L, l=(M$, $t, B)$ and consisting of the route of the logistical chain carrying grouped goods $M\left[k_{1}, \ldots, k_{n}\right]$, where $\forall{ }_{1 \leq i \leq n}$ $k_{i} \in K$; the time period of carriage $t:\{1, \ldots, n-1\} \rightarrow N$ between two terminals, the length of the links $B:\{1, \ldots, n$ $1\} \rightarrow N$.

c) A set of connections between non-oriented trading regions and transport terminals $L_{R} \subset T \times K$. Thus, each 
trading region is connected: $\forall Z_{Z \in \mathrm{K}} \exists_{k} \in \mathrm{K}_{\mathrm{K}}(Z, k) \in L_{R}$.

d) The numbers of terminals $I: K \rightarrow N$.

e) The coordinates of terminals $X Y: \mathrm{K} \rightarrow N \times N$.

f) The kind of transport and their combinations $Q$ : $L \rightarrow\{$ road, railway $\}$.

g) The length of distances between terminals and links $B: L_{R} \rightarrow N, m$.

Let sign link $l_{1}$ between $k_{1}$ and $k_{2}, l_{2}$ - between $k_{2}$ and $k_{3} ; l_{3}$ - between $k_{3}$ and $k_{4} ; l_{4}$ - between $k_{4}$ and $k_{5} ; l_{5}$ between $k_{5}$ and $k_{6} ; l_{6}$ - between $k_{6}$ and $k_{7} ; l_{7}$ - between $k_{2}$ and $k_{11} ; l_{8}$ - between $k_{11}$ and $k_{8} ; l_{9}$ - between $k_{5}$ and $k_{8} ; l_{10}$ - between $k_{5}$ and $k_{9} ; l_{11}$ - between $k_{9}$ and $k_{10}$.

The network $G_{R}=\left(K, L, L_{R}, I, X Y, Q, B\right)$ in the given example before planning consists of a set of nodes $K^{A}=\left\{k_{1}\right.$, $\left.k_{2}, k_{3}, k_{4}, k_{5}, k_{6}\right\}$ and set of links $L^{A}\left\{l_{1}, l_{2}, l_{3}, l_{4}, l_{5}\right\}$.

The network of the logistical routes of grouped goods at the planning stage consists of a set of nodes (terminals) $-K^{P}=K^{4} \cup\left\{k_{8}, k_{5}, k_{9}, k_{10}\right\}$ and a set of links (logistical junctions) $L^{P}=L^{A} \cup\left\{l_{9}, l_{10}, l_{11}\right\}$. Terminal $k_{9}$ could be a multimodal terminal.

The following sizes can be defined in the territory $T$ being researched and the logistical network $\mathrm{G}_{R}=(K, L$, $\left.L_{R}, I, X Y, Q, B\right)$ :

a) A full list of trinominals consisting of two nodes (terminals) and links connecting them (logistical junctions) $m_{r}=\left[\left(k_{1}, l_{1}, \mathrm{k}_{2}\right),\left(k_{2}, l_{2}, k_{3}\right), \ldots,\left(k_{\mathrm{m} \cdot \max -1}, l_{\mathrm{m} \cdot \max -1}, k_{\mathrm{m} \cdot \max }\right)\right]$ will be referred to as a logistical chain:

$$
-\forall_{1 \leq i \leq m \cdot \max }: k_{i} \neq k_{j} \text {. }
$$

b) The route of on-line grouped goods $m_{r}=\left[\left(k_{1}, l_{1}\right.\right.$, $\left.\left.k_{2}\right),\left(k_{2}, l_{2}, k_{3}\right), \ldots,\left(k_{\text {m.max }-1}, l_{\text {m.max }-1}, k_{\text {m.max }}\right)\right]$ can be referred to as logistical connections between consignments region of origin $Z_{s}$ and the accepting region $Z_{a}$, if the following equations are true:

$$
\begin{aligned}
& \left(Z_{s}, k_{1}\right) \in L_{R}, \\
& \left(Z_{a}, k_{\text {m.max }}\right) \in L_{R}, \\
& Z_{s} \neq Z_{a} .
\end{aligned}
$$

c) A set of all of the connections from $Z_{s}$ (dispatching region) to $Z_{a}$ (accepting region) is described as:

$\operatorname{Mr}\left(Z_{s}, Z_{a}\right)=\left\{m \mid m\right.$ logistical conection from $Z_{s} i$ to $\left.Z_{a}\right\}$.

d) The quality of carrying a single unit of goods from one terminal to another one $\left(k_{i}, l_{i}, k_{i+1}\right)$, where:

$$
\pi\left(l_{i}, M, d\right)=k_{i} \wedge \pi\left(l_{i}, M, g\right)=k_{i+1} \wedge d<g .
$$

It can be interpreted as follows:

$$
\lambda_{f}\left(k_{i}, l_{i}, k_{i+1}\right)=\sum_{d \leq j \leq g} l_{i} \cdot t(j) .
$$

e) The quality of the route servicing intended for grouped goods $m_{\mathrm{r}}=\left[\left(k_{1}, l_{1}, k_{2}\right),\left(k_{2}, l_{2}, k_{3}\right), \ldots,\left(k_{m \cdot \max -1}\right.\right.$, $\left.\left.l_{m \cdot \max -1}, k_{m \cdot \max }\right)\right] \in M_{\mathrm{r}}\left(Z_{s}, Z_{a}\right)$ can be expressed as:

$\lambda_{r}\left(Z_{s}, Z_{a}, m\right)=\lambda_{i}\left(i, k_{1}\right)+\lambda_{m}(m)+\lambda_{a}\left(a, k_{m \cdot \max }\right)$, or in other words (in terms of time) can be evaluated as the total time needed for loading, carrying and unloading.

f) A route for carrying grouped goods between two regions $\mathrm{Z}_{s}, \mathrm{Z}_{a} \in T$ can be defined as:

$$
A_{r}\left(Z_{s}, Z_{a}\right)=\operatorname{Min}\left\{\lambda_{r}\left(Z_{s}, Z_{a}, m\right) \mid m \in M_{r}\left(Z_{s}, Z_{a}\right)\right\} .(17)
$$

g) The route for carrying grouped goods which is being planned $m \in M_{r}\left(Z_{s}, Z_{a}\right)$ from $Z_{s}$ to $Z_{a}$, is considered to be the best one provided:

$$
\lambda_{r}\left(Z_{s}, Z_{a}, m\right)=A_{r}\left(Z_{s}, Z_{a}\right) .
$$

The transport network of the territory being researched intended for grouped carriage of goods will be marked $G_{B}$, where $\mathrm{G}_{B}=\left(K, L, L_{B}, I, X Y, Q, B\right)$. This fragment of the network is composed of:

a) $K-$ a complete set of transport terminals located in the network fragment;

b) $L$ - a set of links, defined as $l \in L, l=(M, t, B)$ and consisting of the route of on-line grouped goods $M\left[k_{1}, \ldots, k_{n}\right]$, when $\forall{ }_{1 \leq i \leq n} k_{i} \in K$; the time period of carriage $t:\left\{\mathrm{k}_{1}, \ldots, \mathrm{k}_{n-1}\right\} \rightarrow$ between two terminals, the length of the links $B:\left\{\mathrm{k}_{1}, \ldots, \mathrm{k}_{n-1}\right\} \rightarrow \mathrm{k}_{N}$.

c) A set of connections between non-oriented transport regions and transport terminals $L_{B} \subset T \times K$. Thus, each trading region is connected: $\forall{ }_{Z \in \mathrm{K}} \exists_{k \in \mathrm{K}}(Z, k) \in L_{R}$.

d) The numbers of terminals $I: K \rightarrow N$.

e) The coordinates of terminals $X Y: \mathrm{K} \rightarrow N \times N$.

f) The means of transport and their combinations $Q: L \rightarrow\{$ road, railway $\}$.

g) The length $B: L_{R} \rightarrow N, m$ of distances between terminals and links.

Goods can be transported by a generally established order in the given network fragment $\mathrm{G}_{B}=\left(K, L, L_{B}, I, X Y, Q\right.$, $B)$ or grouped in the network fragment $\mathrm{G}_{R}=(K, L, L, I, X Y$, $Q, R)$. The supply of goods can be expressed as $f\left(Z_{s}, Z_{a} \sigma\right.$, $m) \in N$, where the dispatching region $Z_{s} \in T$, the accepting region $Z_{a} \in T$, a route $m \in M_{B}\left(Z_{s}, Z_{a}\right)$, when $m=B$ or $m \in M_{R}\left(Z_{s}, Z_{a}\right)$, when $m=R$, a way of goods carriage $\sigma \in\{B, R\}$. The supply of goods $\gamma_{s a \sigma m}$ will be a four-dimension matrix of the total $f\left(Z_{s}, Z_{a} \sigma, m\right)$. The selection of the way of goods carriage $\gamma_{s a \sigma}$ will be three-dimension matrix $f\left(Z_{s}, Z_{a} \sigma\right)$. The carriage of all goods from $Z_{s}$ to $Z_{a}$ can be expressed as $f\left(Z_{s}, Z_{a}\right)=f\left(Z_{s}, Z_{a}, B\right)+f\left(Z_{s}, Z_{a} R\right)$. The matrix of all carriages $\gamma_{s a}$ is the matrix of all goods being sent and received. Carriages from the dispatching region $Z_{s}$ are $f_{s}=\Sigma_{a} \in{ }_{T} f\left(Z_{s}, Z_{a}\right)$, i.e. the number of all carriages is related to the dispatching region. The expression of carriages $\gamma_{s}=\left(f_{s}\left(Z_{s}\right), \ldots, f_{s}\left(Z_{t . m a x}\right)\right.$ of the dispatching region $Z_{s}$ is a vector of all the carriages related to the region. Carriages $f_{a}=\Sigma_{i} \in_{T} f\left(Z_{i}, Z_{a}\right)$ occurring in the accepting region $Z_{a}$ are the number of carriages related to the dispatching region. The expression of carriages $\gamma_{a}=\left(f_{a}\left(Z_{a}\right), \ldots, f_{a}\left(Z_{\text {t.max }}\right)\right.$ of the goods received in region $Z_{a}$ is a vector of all the carriages related to this region. 
The analysis and forecast of the matrix of carriages across all the regions enables us to optimize the process of planning of the routes for grouped goods carriage.

\section{Conclusions}

1. The technological tool permitting us to optimize goods carriages is the design of stable routes for carrying on-line grouped goods in accordance with the forecast of the indirect demand and supply of the goods market. This is particularly urgent as the size of shipments in the European Union and Lithuania is gradually diminishing, the number of shipments and feed of delivery frequency, however, is increasing.

2. The analysis and forecast of the matrix of goods carriage among all the regions enables us to optimize the process of planning routes for carriage of on-line grouped goods.

\section{References}

1. Mazura M. Forecasting of the transport activities. Transport, Vol XVII, No 2, Vilnius: Technika, 2002, p. 57-59.

2. Baublys A. Statistical stochastic estimation of technological process of carrying. Transport, Vol XVII, No 4, Vilnius: Technika, 2002, p. 127-136.

3. Keršys A., Jurkauskas A. Prediction and modelling of communication needs. Transport, Vol XVI, No 2, Vilnius: Technika, 2001, p. 70-76.

4. Armacost A. P., Barnhart C., Ware K. A. Composite Variable Formulations for Express Shipment Service Network Design. Transportation Science, Vol 36, No 1, USA: Institute for Operation Research and Management Sciences, 2002, p. 1-20. 